\title{
Meaningful feedback through a sociocultural lens
}

Citation for published version (APA):

Ramani, S., Koenings, K. D., Ginsburg, S., \& van der Vleuten, C. P. M. (2019). Meaningful feedback through a sociocultural lens. Medical Teacher, 41(12), 1342-1352.

https://doi.org/10.1080/0142159X.2019.1656804

Document status and date:

Published: 02/12/2019

DOI:

10.1080/0142159X.2019.1656804

Document Version:

Publisher's PDF, also known as Version of record

Document license:

Taverne

\section{Please check the document version of this publication:}

- A submitted manuscript is the version of the article upon submission and before peer-review. There can be important differences between the submitted version and the official published version of record.

People interested in the research are advised to contact the author for the final version of the publication, or visit the DOI to the publisher's website.

- The final author version and the galley proof are versions of the publication after peer review.

- The final published version features the final layout of the paper including the volume, issue and page numbers.

Link to publication

\footnotetext{
General rights rights.

- You may freely distribute the URL identifying the publication in the public portal. please follow below link for the End User Agreement:

www.umlib.nl/taverne-license

Take down policy

If you believe that this document breaches copyright please contact us at:

repository@maastrichtuniversity.nl

providing details and we will investigate your claim.
}

Copyright and moral rights for the publications made accessible in the public portal are retained by the authors and/or other copyright owners and it is a condition of accessing publications that users recognise and abide by the legal requirements associated with these

- Users may download and print one copy of any publication from the public portal for the purpose of private study or research.

- You may not further distribute the material or use it for any profit-making activity or commercial gain

If the publication is distributed under the terms of Article $25 \mathrm{fa}$ of the Dutch Copyright Act, indicated by the "Taverne" license above, 


\title{
Meaningful feedback through a sociocultural lens
}

\author{
Subha Ramani, Karen D. Könings, Shiphra Ginsburg \& Cees P. M. van der \\ Vleuten
}

To cite this article: Subha Ramani, Karen D. Könings, Shiphra Ginsburg \& Cees P. M. van der Vleuten (2019) Meaningful feedback through a sociocultural lens, Medical Teacher, 41:12, 1342-1352, DOI: 10.1080/0142159X.2019.1656804

To link to this article: https://doi.org/10.1080/0142159X.2019.1656804

曲 Published online: 24 Sep 2019.

Submit your article to this journal $₫$

山ll Article views: 1386

Q View related articles $\llbracket$

View Crossmark data \lceil

4 Citing articles: 3 View citing articles 


\title{
AMEE GUIDE
}

\section{Meaningful feedback through a sociocultural lens}

\author{
Subha Ramani ${ }^{a, b} \mathbb{D}$, Karen D. Könings ${ }^{c}\left(\mathbb{D}\right.$, Shiphra Ginsburg ${ }^{d}$ and Cees P. M. van der Vleuten ${ }^{c}$ \\ ${ }^{a}$ Department of Medicine, Brigham and Women's Hospital, Harvard Medical School, Boston, MA, USA; ${ }^{\mathrm{b}}$ Research and Scholarship, \\ Harvard Macy Institute, Boston, MA, USA; 'Department of Educational Development and Research and the School of Health Professions \\ Education, Faculty of Health, Medicine and Life Sciences, Maastricht University, Maastricht, Netherlands; ${ }^{\mathrm{d} D e p a r t m e n t}$ of Medicine \\ (Respirology) and Wilson Centre for Research in Education, University of Toronto, Toronto, Canada
}

\begin{abstract}
This AMEE guide provides a framework and practical strategies for teachers, learners and institutions to promote meaningful feedback conversations that emphasise performance improvement and professional growth. Recommended strategies are based on recent feedback research and literature, which emphasise the sociocultural nature of these complex interactions. We use key concepts from three theories as the underpinnings of the recommended strategies: sociocultural, politeness and self-determination theories. We view the content and impact of feedback conversations through the perspective of learners, teachers and institutions, always focussing on learner growth. The guide emphasises the role of teachers in forming educational alliances with their learners, setting a safe learning climate, fostering self-awareness about their performance, engaging with learners in informed self-assessment and reflection, and co-creating the learning environment and learning opportunities with their learners. We highlight the role of institutions in enhancing the feedback culture by encouraging a growth mind-set and a learning goal-orientation. Practical advice is provided on techniques and strategies that can be used and applied by learners, teachers and institutions to effectively foster all these elements. Finally, we highlight throughout the critical importance of congruence between the three levels of culture: unwritten values, espoused values and day to day behaviours.
\end{abstract}

\section{Introduction}

The feedback conversation, once a static teacher to learner monologue, is shifting towards a dynamic learner-directed collaborative dialogue. In this AMEE guide, we summarise recent literature on sociocultural factors that influence the quality and impact of feedback in health professions education; propose a new model for viewing feedback exchanges through the lens of learners, teachers and institutions; and conclude with practical feedback strategies to promote a growth-enhancing feedback culture.

\section{The purpose of this guide}

The primary aim of this guide is to assist teachers and learners in engaging in meaningful and actionable feedback conversations, and institutions in establishing a growth-oriented feedback culture. Drawing upon principles from organisational culture as well as sociocultural, politeness and self-determination theories, we emphasise factors that could encourage feedback seeking, acceptance and incorporation and potentially change behaviour. Our model for designing feedback initiatives recommends an optimal balance of learner factors, and teacher and institutional factors. Central to these recommendations are trusting relationships and co-regulation of learning by teachers and learners. Finally, we argue that a growth mind-set is critical for a psychologically safe learning culture.

\section{Practice points}

- Feedback can be considered effective only when it informs learner self-assessment and has an impact on learner growth.

- Feedback conversations are complex interpersonal encounters; dynamic bidirectional conversations are more meaningful than unidirectional top down approaches.

- Credibility promotes feedback acceptance- it is influenced by relationships, educational alliances, direct performance observation and institutional culture.

- Teachers should focus on establishing a safe learning climate, forming trusting educational alliances, engaging in informed self-assessment and facilitated reflection with learners, while attending to learner self-efficacy and autonomy.

- Institutions should address sociocultural factors in feedback initiatives, foster a growth mind-set and prioritise a learning goal-orientation.

- Co-regulation of the educational environment and co-creation of learning opportunities by teachers and learners may be important in promoting growth.

\section{Organisational culture and feedback}

Since culture is central to sociocultural perspectives of feedback, we refer to the three levels of culture described by Edgar Schein, an expert on organisational culture and 


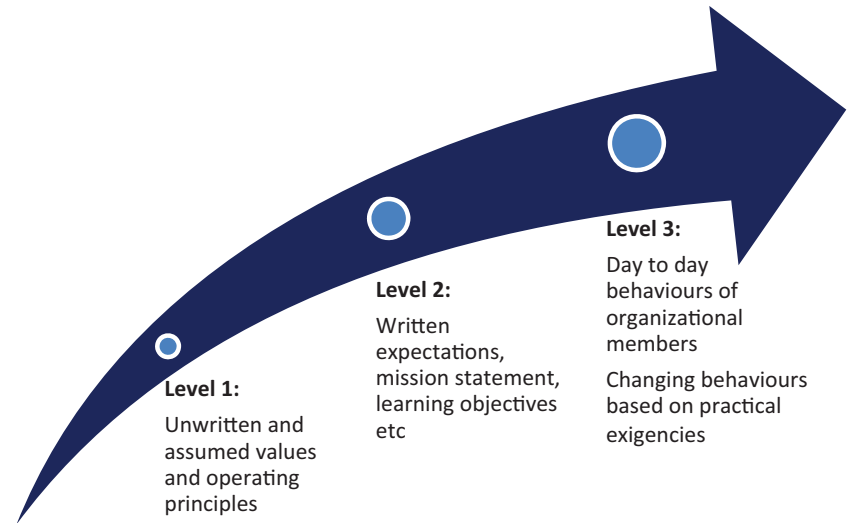

Figure 1. The three levels of organisational culture applied to feedback culture, based on Edgar Schein's model.

behaviour: (1) the deepest level refers to implicit values and unwritten assumptions, (2) the next level refers to written expectations and mission statements and (3) the most visible level depicts day to day behaviour (Schein 2017). Applying these levels to feedback culture (Figure 1), values and assumptions refer to how things are done at the institution and how new members are acculturated, the next level refers to written expectations for feedback, and the visible level refers to feedback behaviours of teachers and learners. Ideally, the three levels would act in concert, in reality they may contradict each other.

\section{Feedback as a sociocultural phenomenon}

Sociocultural factors that influence feedback include: teacher characteristics, teacher-learner relationships, observation of performance, learner self-efficacy, autonomy, feedback seeking and acceptance, and perceived credibility of feedback data (Sargeant et al. 2007, 2008a; Delva et al. 2011; Mann et al. 2011; Sargeant et al. 2011; Eva et al. 2012; Watling et al. 2013a, 2014; Watling 2014a, 2014b, 2016; Ramani, et al. 2017a, 2017b, 2019). Self-assessment and reflection are also central to feedback seeking and acceptance (Sargeant et al. 2008b, 2009; Könings et al. 2016). In medical education, use of vague feedback language is common as faculty wish to avoid threats to friendly working relationships, learner self-esteem and autonomy (Sargeant et al. 2007, 2008a; van de Ridder et al. 2015a, 2015b; Ramani et al. 2018). It is important to discuss learner-related, teacher-related and institution related factors that could enhance perceived feedback credibility and theoretical principles applicable to fostering meaningful feedback.

\section{Linking key theoretical principles to feedback}

Three theories are particularly relevant to sociocultural aspects of feedback: Sociocultural theory, Politeness theory and Self-determination theory. Below, we discuss key principles from these theories that could intersect and help establish a feedback culture of growth (Figure 2).

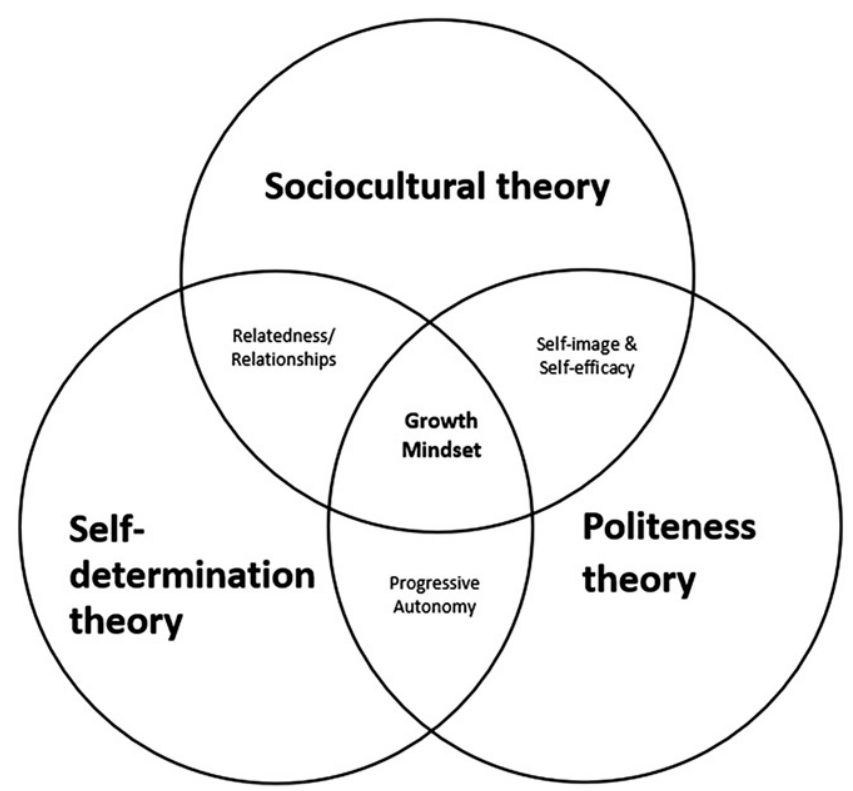

Figure 2. How intersections of sociocultural, politeness and self-determination theories could enhance feedback culture.

\section{Sociocultural theory and feedback}

This theory proposes that learning occurs through interaction, negotiation, and collaboration (Lave and Wenger 1991). Since clinical learning occurs in a community where team members learn from and develop with others, institutions must prioritise teamwork skills among learner competencies. Applying this theory to feedback, institutions can establish explicit expectations for teachers and learners to: discuss learning goals, engage in reflection, calibrate gaps between observed and expected performance and exchange formative feedback to narrow the gap. Adult learners should be encouraged to lead these conversations with teachers acting as coaches. This will help learners to become valuable members in their community of practice (Lave and Wenger 1991).

\section{Politeness theory and feedback}

Politeness theory assumes that many conversations are potential face-threatening acts to the hearer or speaker (Brown and Levinson 1987). Face is categorised as positive (the need to project a positive image) and negative (freedom to act without imposition). In clinical training, positive face can be viewed as learner self-efficacy and negative face as learner autonomy. These traits are particularly important for advanced learners who serve at the frontline of patient care. Such learners may view constructive feedback as "negative" and a breach of the norms of expected politeness. Honest constructive feedback is essential for longitudinal growth, even if affects learners' self-efficacy. However, clinical teachers tend to use predominantly positive language (good job, pleasure to work with) in learner evaluation narratives and feedback conversations, this tendency can be linked to politeness concepts where attention to self-esteem, self-efficacy and autonomy impedes honest constructive narratives and feedback (Ginsburg et al. 2015, 2016; Ramani et al. 2017b, Ramani et al. 2019). 


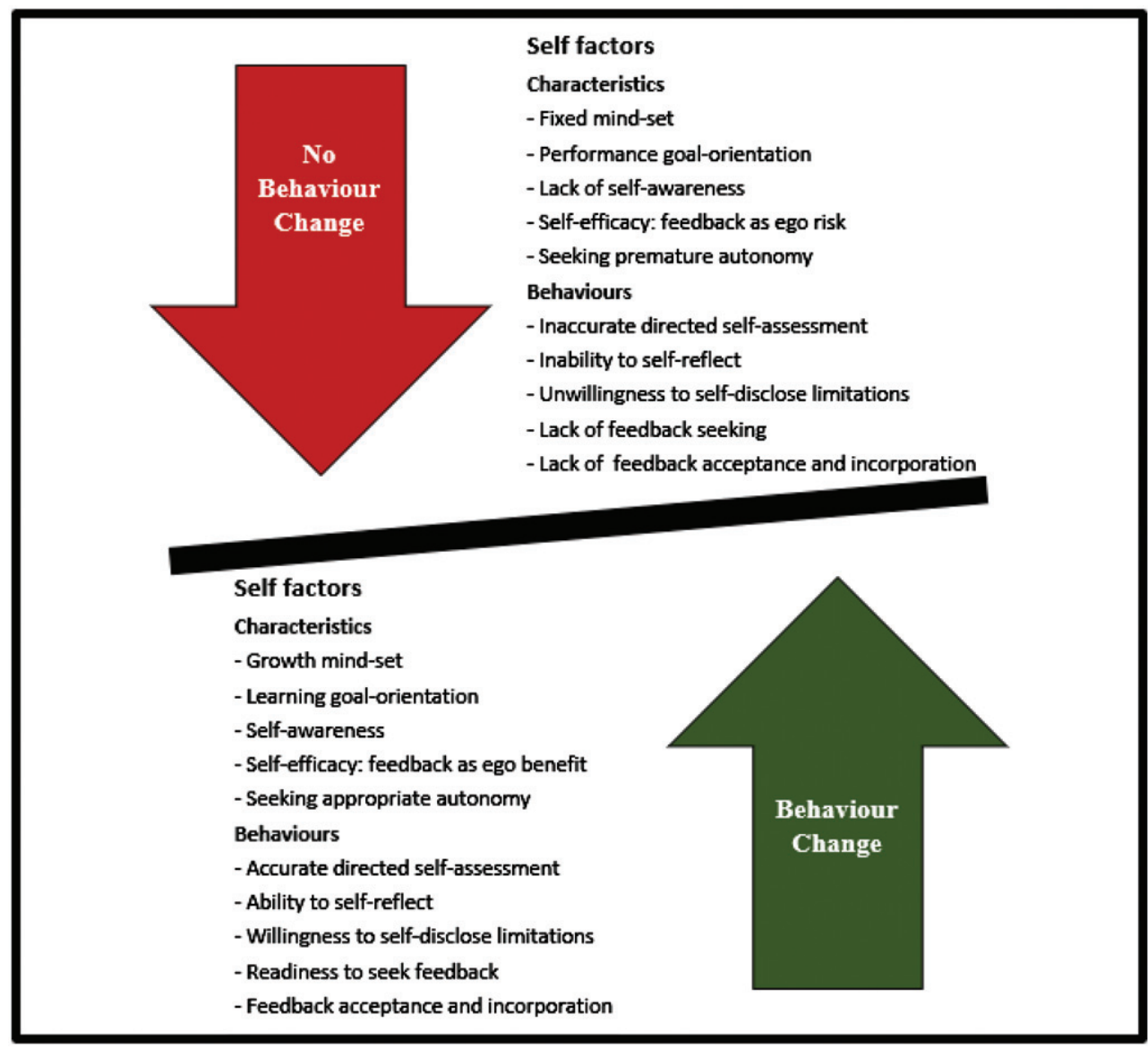

Figure 3. This figure depicts self-factors (characteristics and behaviours) that can impede (downward arrow and trajectory of the see-saw), and those that can facilitate (upward arrow and trajectory of the see-saw) learner assimilation of feedback and willingness to change practice.

\section{Self-determination theory and feedback}

Self-determination theory proposes three key needs that enhance intrinsic motivation: competence, relatedness and autonomy (Ryan and Deci 2000, 2017). Intrinsically motivated learners may be more willing to seek, accept and assimilate feedback, and therefore change behaviour. Since progressive and appropriate autonomy prepares learners for independent practice, the learning culture should actively seek to enhance intrinsic motivation (Mann 2002). Ten Cate et al. suggest three approaches to boost motivation during feedback conversations: shift the focus from the individual to the context; shift from instructional messages to self-regulation; and shift the focus from feedback provider to recipient (Ten Cate et al. 2011; Ten Cate 2013). Feedback, grounded in observed data and facilitated reflection, should occur in a context where longitudinal relationships between teachers and learners are promoted, and learners are provided increasing autonomy based on ability and task complexity (Ramani, et al. 2018, 2019).

\section{Balancing the self and the other: A model for growth- enhancing feedback}

Feedback credibility may require an optimal balance of factors related to 'self' and 'other'. 'Self' refers to learner factors that stimulate feedback seeking and incorporation from multiple sources. The 'other' refers to teacher and institutional factors that could influence learner factors. The self and other co-exist in an institutional context which features an organisational culture as well as a learning culture.

\section{Self-factors and feedback (learner)}

Self-factors that could influence feedback seeking and acceptance include: mind-set, goal-orientation, self-awareness, self-efficacy, and autonomy. The intersection of these factors and feedback behaviours is depicted in Figure 3.

Mind-set. Carol Dweck, a leading researcher in the field of motivation and development, described two core mindsets: a fixed mind-set and a growth mind-set (Dweck 1990, 2016). People with a fixed mind-set believe that success is a result of innate traits such as intelligence and talent, focus on showcasing their skills and perceive failure as a negative statement of their abilities. They are likely to avoid seeking or accepting constructive feedback. Those with a growth mind-set believe that abilities can be developed through hard work and ongoing learning. A growth mind-set would allow learners to seek and accept constructive feedback; disclose limitations as opportunities to expand knowledge and skills; and view failure as a learning opportunity rather than an insult to their abilities.

Goal-orientation. Goal-orientation is an individual's disposition towards developing or validating one's ability in achievement settings (VandeWalle and Cummings 1997; VandeWalle et al. 2000, 2001). Differences between individuals who exhibit helplessness and those who use coping strategies when facing difficult tasks are attributed to two types of achievement goals: (1) task involvement, where individuals seek to develop competence relative to their abilities, and (2) ego involvement, where individuals seek to develop competence relative to others (Nicholls 1979; 


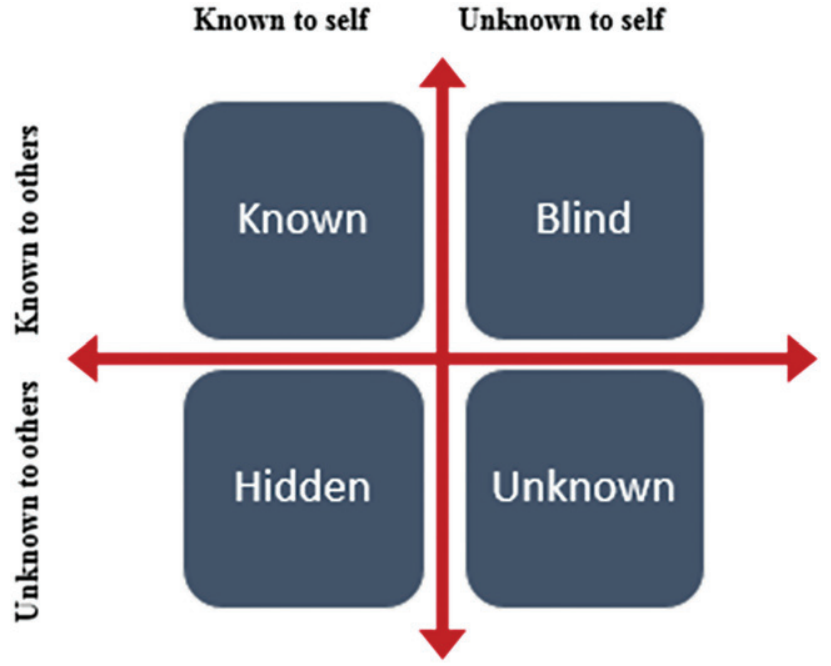

Figure 4. The Johari window model of awareness features four quadrants, each indicating level of knowledge about one's performance or behaviours by self and others.

Dweck 2016). Two types of goal orientation were proposed: learning goal-orientation and performance goal-orientation. Professionals with a performance goal-orientation may focus on creating a good impression and not welcome feedback that could reveal limitations and threaten their image. Professionals with a learning goal-orientation focus on achieving mastery in their field and are more likely to seek and accept constructive feedback.

Self-awareness. Self-awareness refers to one's capacity for analysis and accurate appraisal of own behaviour in different situations. Levels of self-awareness range from confusion (complete unawareness of self) to meta self-awareness (aware of how one is seen through others' eyes) (Dweck 2017). The Johari window, described by psychologists Luft and Ingham, is a two-by-two model that depicts different levels of awareness of behaviours by self and others in human interactions (Luft 1969). The window features four quadrants: open- known to self and others, blind- known to others but unknown to self, hidden- known to self but unknown to others, and unknown- unknown to self and others (Figure 4). To enhance self-awareness, learners should seek feedback to learn about behaviours that they are unaware of, disclose limitations for teachers to provide accurate feedback based on context, and engage in selfdiscovery through acceptance of performance data from multiple sources to bring unknown areas to light (Ramani et al. 2017a).

Self-efficacy. Self-esteem (overall sense of self-worth) as well as self-efficacy (confidence in one's ability to succeed professionally) influence how individuals think, behave and feel (Bandura 1977; Lane et al. 2004). In academic settings, previous accomplishments are a powerful source of selfefficacy and motivate professionals to overcome challenges (Bandura 1977, 1997). Applying these principles to feedback, learners with increased self-efficacy may become more self-aware, internally motivated to face challenges, overcome obstacles and succeed in their practice. Thus, they are more likely to engage in self-assessment, feedback seeking and acceptance, reflection on performance and committment to behaviour change.
Autonomy. Human behaviours can be initiated and regulated through choice (autonomous), driven by external factors (controlled), or a combination (Deci and Ryan 1985; Ryan and Deci 2000). Autonomy, the desire to act independently, has a major impact on internal motivation, creative thinking and action (Deci and Ryan 1985; Ryan and Deci 2017). Autonomy-supportive work environments can enhance intrinsic motivation while controlling contexts could undermine motivation. Although positive feedback can affirm learners' self-efficacy, vague positive comments alone are not autonomy-supportive since specific constructive feedback and concrete action plans for improvement are crucial for independent practice (Kusurkar et al 2011a, 2011b).

\section{Other factors- The teacher and institution}

Teacher and institution-related factors strongly influence learner-related factors discussed above. Although institutional factors influence teacher characteristics and behaviours, we include both under 'other' since our model views feedback through the lens of the learner. Figure 5 is a proposed model of self-factors and other-factors co-existing within an institutional context composed of an organisational culture as well as a learning culture. Teacher-related factors include: addressing self-efficacy, providing autonomy and enhancing self-awareness (Box 1 depicts samples of teacher statements and strategies); and institutionrelated factors include: optimising mind-set and goal-orientation (Box 2 shows samples of mission statements with explicit guidelines for feedback exchanges).

\section{Teacher-related factors}

Addressing self-efficacy. Self-efficacy increases internal motivation and willingness to face challenges and arises from previous accomplishments (Bandura 1977; Lane et al. 2004). Teachers can help learners recall previous professional successes and navigate obstacles when faced with new tasks. Teachers need to support as well as challenge learners to help them grow (Daloz and Daloz 1999). Since unguided self-assessment is often inaccurate (Regehr and Eva 2006; Eva and Regehr 2008, 2011) and learners reject feedback that conflicts with their self-assessment (Mann et al. 2011), teachers can guide accurate calibration of learner performance through facilitated reflection and informed self-assessment using data from multiple sources (Boud 1995; Sargeant et al. 2008b, 2010). In summary, teachers can enhance learners' self-efficacy by discussing previous successes, reinforcing behaviours that contributed to success (support), encouraging them to tackle new and complex tasks (challenge), and providing constructive feedback to assist them in succeeding at new tasks.

Providing autonomy. Autonomy exerts a strong influence on internal motivation (Deci and Flaste 1995). Ten Cate et al. proposed a model to guide teachers in balancing supervision and autonomy based on learner level and ability, and gradually moving along an autonomy spectrum from full external regulation to full self-regulation of learning (Ten Cate et al. 2004). The speed of progress along this continuum will vary based on learner capability to successfully perform different clinical tasks (Ten Cate et al. 2004). 


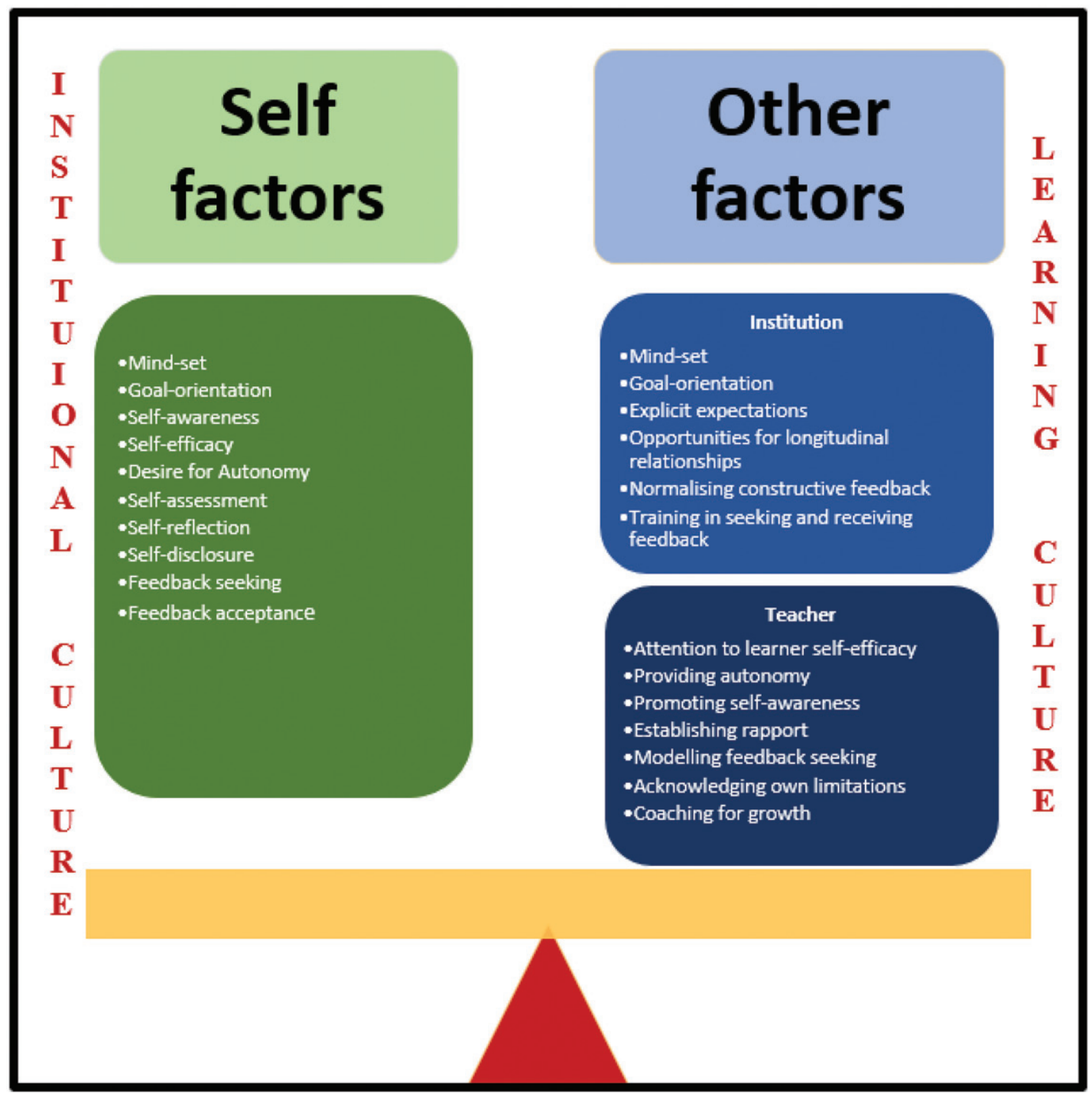

Figure 5. This is a proposed model of how a balance of self-factors and other-factors can promote behaviour change among learners. We also show self and other factors as co-existing within an institutional context composed of both an organisational culture as well as a learning culture.

Balancing supervision and autonomy challenges most clinical teachers, but safe patient care mandates this balance. Optimising the balance between guidance and self-regulation, termed 'constructive friction' between teaching and learning (Vermunt and Verloop 1999), can occur through feedback and reflection. Participatory design, where teachers and learners co-create learning environments, has a positive effect on learner attitudes, motivation and committment (Könings et al. 2005, 2014). Teachers can encourage learners to take ownership of their learning by asking them to formulate learning goals, facilitating reflection, providing feedback and asking them initiate action plans for progression to the next level.

Enhancing self-awareness. Self-awareness, the ability to calibrate one's behaviours accurately and objectively, helps individuals gain new skills and competencies (Benbassat and Baumal 2005). It is a dynamic process with two facets: internal (recognising own inner state), and external (recognising impact on others) (Goleman 1998). In clinical education settings, self-awareness develops with others rather than independently (Rochat et al. 2012). Awareness of one's abilities, assumptions and reactions can help learners understand how their actions are perceived by others including patients and handle challenging clinical situations better (Novack et al. 1997, 1999). Strategies that teachers can use to develop learner self-awareness include: application of the Johari window model to feedback conversations (Luft 1969; Ramani et al. 2017a), developing an educational alliance, facilitating reflection of performance, debriefing challenging clinical situations, sharing own challenges and limitations and stimulating self-discovery (Sargeant et al. 2008a, 2008b, 2010, 2015; Sargeant 2015; Telio et al. 2015, 2016; Armson et al. 2019).

Box 1. Examples of teacher statements to effectively address teacher related factors:

Addressing self-efficacy

"We had discussed that one of your strengths has been patient communication skills and your patients have emphasised this when we have been in the room together. Would you now like to focus on enhancing your communication skills even further, building on your strong foundation?"

"I observed that measuring the venous pressure and diagnosing volume status seemed challenging to you. Do you think my observation is accurate? It is a difficult skill to master and it took me years to get comfortable at this examination. How about if I demonstrate the tricks that I have learned from my clinical teachers which you might find useful?"

Providing autonomy*

"I like observing my learners when they interact with patients. This informs me how I can help in your own growth as a clinician. What would you like me to focus on as I observe you with this patient today?" 
* In the patient room, teachers should position themselves to be unobtrusive, show respect for the learners as the primary caregivers and not take over the conversation with patients.

Enhancing self-awareness

"When you counselled the patient today, what strategies do you think were most effective? What did you find most challenging?"

If learners are unaware of a behaviour, the following could be helpful: "One thing I observed was the patient was slightly confused when you were explaining about their heart attack, what investigations and treatment you had planned. All of us tend to provide patients with too much clinical information but may not stop to ensure their understanding. Clearly, we have good intentions, but it is well worth making sure that they know what is going on."

\section{Institution-related factors}

Fostering growth mind-set. Of the two mind-sets described by Carol Dweck, a growth mind-set is more desirable among learners who aim to gain new knowledge, learn new skills and perform new and complex tasks (Dweck 2016). Institutions can foster a growth mind-set so that learners can cope with challenges and setbacks, seek and receive constructive feedback and treat failure as a learning opportunity. Lack of longitudinal relationships in clinical training makes it challenging to build educational alliances and exchange honest constructive feedback (Sargeant et al. 2008a, 2008b; Watling et al. 2013a; Watling 2014a; van de Ridder et al. 2015a, 2015b). Therefore, institutions should create opportunities for longitudinal teacher-learner relationships, normalise exchange of constructive feedback, and prioritise performance improvement through a growth mind-set.

Fostering learning goal-orientation. Goal orientation significantly influences intrinsic motivation among individuals (Nicholls 1979). A learning goal orientation allows learners to seek feedback and accept constructive feedback as a means of correcting deficiencies and improving future performance (Sargeant et al. 2011; van de Ridder et al. 2014). Performance goal orientation, further categorised as avoidant (avoidance of failure) and prove (proving competence), dominates in a learning environment that emphasises summative assessments and assessment 'of' rather than 'for' learning (VandeWalle and Cummings 1997). Institutions can foster a learner-centred formative assessment culture by focussing on competence and mastery of tasks rather than self-image, and through regular performance-based feedback. Programmatic assessment is a model that encourages such an approach to assessment (van der Vleuten et al. 2012). Learning environments cocreated by teachers, learners and institutional leaders could promote a culture of proactive feedback seeking, acceptance of constructive feedback and bidirectional feedback (Könings et al. 2005, 2014). Co- creation is challenging to implement and requires institutional leaders to explicitly champion and model the process (Harrison et al. 2017).

Box 2. Examples of mission statements to address institution-related factors

Fostering growth mind-set

All professionals, teachers, learners and leaders, have strengths and areas for improvement. Our institution focusses on continuous quality improvement at all levels. Frequent performance appraisal and reinforcing as well as constructive feedback are key for growth.

Fostering learning goal-orientation

It is important that teachers and learners establish goals to target ongoing learning and professional growth. These goals should direct feedback conversations, Learning occurs when current performance is calibrated against expected performance and feedback focusses on closing the gap between the two.

The purpose of assessment and feedback is to maximise each individual's unique strengths, identify and work on areas for improvement and fulfill their potential.

\section{Practical strategies to optimise the balance of learner, teacher and institutional feedback factors}

To be considered effective, feedback should impact learner behaviour (Delva et al. 2011; Molloy and Boud 2013; Boud 2015), but sociocultural factors strongly influence perceptions of feedback credibility and acceptance (Bing-You et al. 1997; Sargeant et al. 2007, 2008a, 2011; Watling et al. 2013a; Watling 2014a, 2014b; van de Ridder et al. 2014, 2015a; Bing-You et al. 2017). Furthermore, acceptance and incorporation of feedback may lead to behaviour change, though more research is needed in this area (van de Ridder et al. 2014). Rather than focussing on teacher feedback techniques alone, feedback conversations should be viewed as an interplay between learners and teachers with the ultimate goal of learner growth (Ramani et al. 2019). Teacher and institutional factors were combined in the previous section, however, in this section teacher and learner strategies are combined to highlight teacher-learner relationships as well as co-creation of the learning environment (Figure 6).

\section{Strategies for teachers and learners to co-create mean- ingful feedback}

A psychologically safe space is essential for meaningful feedback conversations, where educational alliances are developed, self-esteem and autonomy are addressed, and co-creation of learning experiences occur.

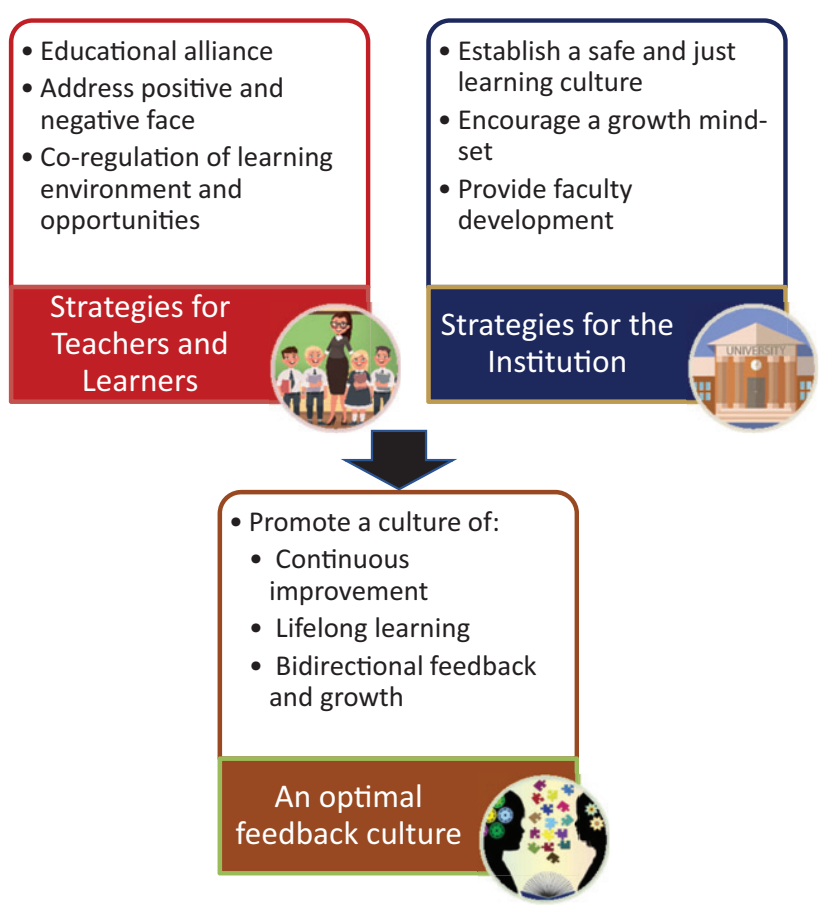

Figure 6. Feedback strategies for learners, teachers and institutions that address sociocultural principles. 
Educational alliances. Feedback initiatives that focus on teacher techniques have not resolved the mismatch of perceptions between teachers and learners on the adequacy and quality of feedback (Bing-You et al. 1997; Sender Liberman et al. 2005; Bing-You and Trowbridge 2009; BingYou et al. 2017). Newer models place learners at the heart of feedback exchanges and emphasise a congenial teacherlearner educational alliance (Telio et al. 2015, 2016). Interpersonal communication theories emphasise four key elements in one-on-one communications: persons communicating, context of the communication, relationship between the persons and content of the communication (Bylund et al. 2012). Based on these elements and recent feedback literature (Sargeant et al. 2009, 2011, 2015), we recommend the following strategies for teachers and depict a sample conversation in Box 3:

- Establish rapport with learners

- Encourage learners to discuss their learning goals

- Promote self-assessment on strengths and challenges

- Facilitate self-reflection

- Provide reinforcing and constructive feedback

- Acknowledge and address emotional responses

- Guide learners in formulating action plans for improvement

Coaching, a technique used in many professions such as music, sports and management, is increasingly included in faculty development for health professions educators to help them guide their learners towards independent practice and professional growth (Gavriel 2016; Rangachari et al. 2017; Lovell 2018; Armson et al. 2019; Watling and LaDonna 2019). The R2C2 (relationships, reaction, content and coaching) model by Sargeant et al. strongly emphasises relationships and use of coaching strategies during feedback conversations (Sargeant et al. 2015, 2017, 2018).

Box 3. Example of a feedback conversation to establish an educational alliance

Teacher: We will be working together for the next week and I am interested in knowing what areas of knowledge or skills you would like to work on during this time.

Learner: I would like to improve my physical examination skills (non-specific).

Teacher: That is a good goal. Since physical examination is a vast area, why don't we narrow your goal to a specific organ system or aspect of physical examination that you find challenging?

Learner: I have trouble with the cardiovascular examination.

Teacher: We can certainly work on that together. Are there aspects of the cardiovascular examination that you are having more difficulty with?

Learner: I find it hard to assess the volume status and also don't know what to do next when I think I hear a cardiac murmur.

Teacher: Excellent. I can demonstrate the examination, observe you when you are performing the examination and give you feedback afterwards on things you did well and things you can improve. Does that sound good to you?

Learner: That will be very helpful to me.

Teacher: When you are with patients, there will likely be other important skills that would catch my attention. I would also provide some feedback on those. Does that sound okay to you? Learner: Yes, it does. Thank you.

Addressing learner self-esteem and autonomy. Politeness theory, which views most interpersonal interactions as a potential threat to the 'face' of the speaker or the recipient, is relevant to feedback conversations (Brown and Levinson
1987). Clinical teachers tend to avoid language that could damage learner self-efficacy (positive face) and actions that threaten their autonomy (negative face), while learners reject feedback if they doubt its credibility or the information conflicts with their self-assessment (Sargeant et al. 2005, 2007, 2008a; Watling et al. 2013a; Watling 2014b). Though learners indicate that direct observation of performance enhances credibility of feedback, they also view this as a potential infringement on autonomy (Watling 2014a, Sargeant et al. 2008a, 2011; Watling 2016, LaDonna et al. 2017; Ramani et al. 2018). Premature autonomy could lead to errors in patient care, therefore teachers need to balance supervision with autonomy appropriate for a given learner. Self-efficacy (positive face) and autonomy (negative face) could be optimally addressed using the following strategies:

- Focus constructive feedback on performance improvement and professional growth

- Use reinforcement of previous successes to guide discussion of areas for improvement

- Orient feedback towards learner goals

- Emphasise that autonomy is developmental; balance of supervision and autonomy depends on learner level and abilities

- Require ongoing direct observation of learner performance, regardless of stage of training

\section{Co-regulation of learning by teachers and learners}

Advanced clinical trainees are front line patient care providers developing into independent practitioners and their relationships with patients and autonomy need to be preserved. As they gain new knowledge and skills, learners should engage in self-regulation of practice through establishment of learning goals, feedback seeking, reflection and incorporation of feedback into practice. Co-regulated learning is described as a process of interdependency between learners and their supervising faculty as they share common patient care goals (Rich 2017). A participatory design feedback loop for co-regulated learning consists of goaldirected feedback, self-assessment, reflection, and development of action plans (Ramani et al. 2019). We recommend the following strategies for co-regulation of learning and depict a sample conversation in Box 4:

- Teachers:

- Establish a safe learning environment where learners can disclose challenges and fears

- Normalise presence of strengths as well as deficiencies

- Perform direct observation of learner clinical performance

- Learners:

- Are empowered to actively engage in and initiate feedback conversations

- Formulate performance improvement plans guided by teachers

- Learners and teachers co-create new learning opportunities to implement action plans 
Box 4. Example of a feedback conversation for co-regulation of learning

Teacher: We will be working together for the next 2 weeks and during this time we will have many brief feedback conversations. Can we start by discussing your learning goals for this rotation? This will ensure that my teaching can help you to achieve those goals, I can focus my observations on specific areas that you are interested in, and we can reflect on what went well and what could be improved. Learner: Okay. In the last rotation, I was having trouble with balancing open-ended questions and asking a comprehensive list of closed-ended questions during history taking. I would appreciate some guidance on this.

Teacher: This is a very good goal to improve history taking and we can certainly work together on this.

Learner: Another area I find challenging is the Neurological examination. It is so detailed, and I am unable to synthesise the findings and localise the lesion.

Teacher: That is very true. I needed to practice a lot before I became comfortable with this examination. One other thing, I believe that our feedback conversations should prioritise your goals, improve your skills and help you grow. Therefore, there are always areas that would need change and improvement. I hope you agree with this approach.

Learner: That sounds like a good approach and I agree with this plan. I want to know my strengths and where I can improve.

Teacher: I prefer to start by asking you to reflect on your strengths and areas for improvement, come up with next steps, and formulate some action plans for improvement. I will reinforce your reflections, add my insights and together we can finalise action plans. What do you think of this plan?

Learner: I have never done this before, so I will need your help in reflecting on my performance and coming up with next steps. But $I$ think this strategy will help me to assess my own performance and become more self-directed in the future. I definitely want to engage in this type of conversation.

Teacher: This sounds like a great plan in which both of us will learn and grow together. In addition, I would like you to tell me what I am doing well as a teacher and how I can be more useful and effective to you. I am excited to work on these reflections together; soon you will become very comfortable in going to your teachers, communicating your learning goals, seeking feedback on those goals, reflecting on your performance and coming up with your own action plans to move to the next level.

Learner: I am very excited to try this approach and continue to improve. Thank you.

\section{Strategies for institutions to establish a culture of growth}

Educational institutions should establish explicit expectations for frequency, content and process of feedback conversations and prioritise a growth mind-set among teachers and learners.

Establish a conducive feedback culture. Recent feedback research indicates that institutional culture has a major impact on feedback (Watling et al. 2014; Watling 2015; Ramani et al. 2017b). The learning culture at many medical institutions worldwide does not promote longitudinal teacher-learner relationships, regular direct observation of performance and specific but non-threatening constructive feedback (Watling et al. 2013b, 2014; Watling 2014a; Ramani et al. 2017a, 2017b, 2018). Even a polite and nurturing institutional culture was not viewed as conducive to honest, meaningful feedback exchanges (Ramani et al. 2017b, 2018), thus the following strategies could be useful:

- Design assessment systems that calibrate learners against expected outcomes rather than peers

- Focus feedback conversations on narrowing gaps between observed and expected outcomes
- Create opportunities for teacher-learner longitudinal relationships with regular discussions of goals and action plans

- Establish expectations for teachers to observe snapshots of learner performance throughout their training

- Provide training in feedback seeking and acceptance

In addition, a safe and just organisational culture could enhance trusting relationships and foster lifelong learning (Frankel et al. 2006; Boysen 2013; Rider et al. 2018) through the following strategies:

- Acknowledge that all professionals have strengths and weaknesses

- Promote willingness to seek help appropriately

- Focus on humanism and accountability to patients

- Empower learners to take ownership of their professional growth

- Enable collaborative bidirectional feedback

- Focus on reflective practice

Prioritise a growth mind-set. Feedback seeking, acceptance and assimilation by learners are essential to promote behaviour change (Cantillon and Sargeant 2008; Sargeant et al. 2011; Watling et al. 2012; Watling 2014b; Sargeant 2015; Sargeant et al. 2015; Watling 2015). A culture of summative assessment and peer comparisons can instill a fixed mind-set among learners (Harrison et al. 2016; Watling and Ginsburg 2019). To inculcate a growth mind-set, the following institutional strategies may be helpful (Ramani et al. 2019):

- Create a culture of assessment for learning rather than assessment of limitations

- Design an assessment system which includes ongoing formative assessment and encourages informed self-assessment

- Encourage learners to take responsibility for calibrating their performance gaps and formulating improvement plans

- Emphasise mastery learning rather than exam performance

- Promote lifelong learning and critical thinking rather than just acquisition of knowledge

- Create opportunities where learners showcase learning goals rather than performance goals

Faculty development. Rather than training only to give feedback, faculty development initiatives should target sociocultural factors that influence this powerful social interaction. We recommend that faculty development initiatives encourage teachers to apply the following strategies:

- Establish a safe learning environment that encourages disclosure of limitations and insecurities

- Facilitate feedback-seeking through rapport building, demonstration of beneficence and engagement in learner growth

- Address learner self-efficacy and provide autonomy appropriate to learner level and ability

- Perform direct observation and accurate calibration of learner performance 
- Engage in facilitated reflection and informed self-assessment (strengths and gaps) with learners using assessment data from multiple sources

- Exchange constructive feedback using specific language targeting observed behaviours without damaging self-efficacy

- Apply coaching strategies during feedback conversations

- Establish a climate of bidirectional feedback through role-modelling of feedback seeking, admission of limitations and lifelong learning by teachers

\section{Conclusions}

In this guide, we have discussed in detail some of the sociocultural factors that influence feedback conversations and learner growth, linking these to principles of organisational culture and three fundamental psychological theories. Despite efforts at many institutions to facilitate a nonthreatening learning climate, the hierarchical educational culture continues to impede bidirectional feedback. It would be important for teachers and learners to actively seek, accept and incorporate reinforcing as well as constructive feedback, and engage in lifelong learning and continuous improvement. We believe co-creation of the learning culture is the right strategy to achieve meaningful feedback conversations and a growth mind-set.

\section{Disclosure statement}

The authors report no conflicts of interest. The authors alone are responsible for the content and writing of the article.

\section{Glossary}

Organisational culture: Three levels of culture have been described: (1) the deepest level refers to unwritten assumptions and implicit values of the organisation, (2) the second level refers to written expectations and mission statements and (3) the most visible level depicts day to day behaviour.

Politeness theory: This theory assumes that most conversations are potential face-threatening acts either to the hearer or speaker. Face has been categorised as positive face (the need to project a positive image to others) and negative face (freedom to act without imposition).

Mind-set: Is a concept developed by the psychologist Carol Dweck. People with a fixed mind-set believe that their success is a result of fixed traits such as innate intelligence, talent and ability. They tend to spend more time showcasing their skills and perceive failure as a negative statement of their abilities. Those with a growth mind-set believe that innate abilities can be developed through hard work, training, and ongoing learning, and view failure as an essential stop on the journey to further learning.

\section{Notes on contributors}

Dr, Subha Ramani is Director, Program for Research, Innovations and Scholarship, Department of Medicine, Brigham and Women's Hospital; Leader of Research and Scholarhip, Harvard Macy Institute; and Associate Professor of Medicine, Harvard Medical School, Boston, MA, USA.

Dr, Karen D. Könings is Associate Professor in the Department of Educational Development and Research and the School of Health
Professions Education, Faculty of Health, Medicine and Life Sciences at Maastricht University, Maastricht, the Netherlands.

Dr, Shiphra Ginsburg is Professor of Medicine (Respirology) and Scientist at the Wilson Center for Research in Education, University of Toronto, Toronto, Canada.

Dr, Cees P. M. van der Vleuten is the Director of the School of Health Professions Education and Professor of Education, Department of Educational Development and Research, Faculty of Health, Medicine and Life Sciences at Maastricht University, Maastricht, the Netherlands.

\section{ORCID}

Subha Ramani iD http://orcid.org/0000-0002-8360-4031 Karen D. Könings iD http://orcid.org/0000-0003-0063-8218 Cees P. M. van der Vleuten (iD) http://orcid.org/0000-0001-6802-3119

\section{References}

Armson H, Lockyer JM, Zetkulic M, Konings KD, Sargeant J. 2019. Identifying coaching skills to improve feedback use in postgraduate medical education. Med Educ. 53(5):477-493.

Bandura A. 1977. Self-efficacy: toward a unifying theory of behavioral change. Psychol Rev. 84(2):191-215.

Bandura A. 1997. Self-efficacy: the exercise of control. New York (NY): W.H. Freeman.

Benbassat J, Baumal R. 2005. Enhancing self-awareness in medical students: an overview of teaching approaches. Acad Med. 80(2): 156-161.

Bing-You R, Hayes V, Varaklis K, Trowbridge R, Kemp H, McKelvy D. 2017. Feedback for learners in medical education: what is known? A scoping review. Acad Med. 92(9):1346-1354.

Bing-You RG, Paterson J, Levine MA. 1997. Feedback falling on deaf ears: residents' receptivity to feedback tempered by sender credibility. Med Teach. 19(1):40-44.

Bing-You RG, Trowbridge RL. 2009. Why medical educators may be failing at feedback. JAMA. 302(12):1330-1331.

Boud D. 1995. Enhancing learning through self assessment. London: Kogan Page.

Boud D. 2015. Feedback: ensuring that it leads to enhanced learning. Clin Teach. 12(1):3-7.

Boysen PG. 2nd. 2013. Just culture: a foundation for balanced accountability and patient safety. Ochsner J. 13(3):400-406.

Brown P, Levinson SC. 1987. Politeness: some universals in language usage. Cambridge Cambridgeshire: Cambridge University Press. (Studies in interactional sociolinguistics; 4).

Bylund $\mathrm{CL}$, Peterson EB, Cameron KA. 2012. A practitioner's guide to interpersonal communication theory: an overview and exploration of selected theories. Patient Educ Couns. 87(3):261-267.

Cantillon P, Sargeant J. 2008. Giving feedback in clinical settings. BMJ. 337:a1961

Daloz LA, Daloz LA. 1999. Mentor: guiding the journey of adult learners. 1st ed. San Francisco (CA): Jossey-Bass. (The Jossey-Bass higher and adult education series.

Deci EL, Flaste R. 1995. Why we do what we do: the dynamics of personal autonomy. New York (NY): Putnam's Sons.

Deci EL, Ryan RM. 1985. Intrinsic motivation and self-determination in human behavior. New York (NY): Plenum. (Perspectives in social psychology).

Delva D, Sargeant J, MacLeod T. 2011. Feedback: a perennial problem. Med Teach. 33(10):861-862.

Dweck CS. 1990. Self-theories and goals: their role in motivation, personality, and development. Nebr Symp Motiv. 38:199-235.

Dweck CS. 2016. Mindset: the new psychology of success. Updated ed. New York (NY): Random House.

Dweck CS. 2017. From needs to goals and representations: foundations for a unified theory of motivation, personality, and development. Psychol Rev. 124(6):689-719.

Eva KW, Armson H, Holmboe E, Lockyer J, Loney E, Mann K, Sargeant J. 2012. Factors influencing responsiveness to feedback: on the interplay between fear, confidence, and reasoning processes. Adv Health Sci Educ Theory Pract. 17(1):15-26. 
Eva KW, Regehr G. 2008. "I'll never play professional football" and other fallacies of self-assessment. J Contin Educ Health Prof. 28(1): 14-19.

Eva KW, Regehr G. 2011. Exploring the divergence between self-assessment and self-monitoring. Adv Health Sci Educ Theory Pract. 16(3): 311-329.

Frankel AS, Leonard MW, Denham CR. 2006. Fair and just culture, team behavior, and leadership engagement: the tools to achieve high reliability. Health Serv Res. 41(4 Pt 2):1690-1709.

Gavriel J. 2016. Cognitive behavioural coaching principles and basic tools to support trainees. Educ Prim Care. 27(4):326-329.

Ginsburg S, Regehr G, Lingard L, Eva KW. 2015. Reading between the lines: faculty interpretations of narrative evaluation comments. Med Educ. 49(3):296-306.

Ginsburg S, van der Vleuten C, Eva KW, Lingard L. 2016. Hedging to save face: a linguistic analysis of written comments on in-training evaluation reports. Adv Health Sci Educ Theory Pract. 21(1): 175-188.

Goleman D. 1998. The emotionally competent leader. Healthc Forum J. 41(2):36, 38, 76

Harrison CJ, Konings KD, Dannefer EF, Schuwirth LW, Wass V, van der Vleuten CP. 2016. Factors influencing students' receptivity to formative feedback emerging from different assessment cultures. Perspect Med Educ. 5(5):276-284

Harrison CJ, Konings KD, Schuwirth LWT, Wass V, van der Vleuten C. 2017. Changing the culture of assessment: the dominance of the summative assessment paradigm. BMC Med Educ. 17(1):73.

Könings KD, Brand-Gruwel S, Merriënboer JJG. 2005. Towards more powerful learning environments through combining the perspectives of designers, teachers, and students. Br J Educ Psychol. 75(4): 645-660.

Könings KD, Seidel T, van Merriënboer J. 2014. Participatory design of learning environments: integrating perspectives of students, teachers, and designers. Instr Sci. 42(1):1-9.

Könings $K D$, van Berlo J, Koopmans $R$, Hoogland $H$, Spanjers IA, ten Haaf JA, van der Vleuten CP, van Merrienboer JJ. 2016. Using a smartphone app and coaching group sessions to promote residents' reflection in the workplace. Acad Med. 91(3):365-370.

Kusurkar RA, Croiset G, Ten Cate TJ. 2011a. Twelve tips to stimulate intrinsic motivation in students through autonomy-supportive classroom teaching derived from self-determination theory. Med Teach 33(12):978-982.

Kusurkar RA, Ten Cate TJ, van Asperen M, Croiset G. 2011b. Motivation as an independent and a dependent variable in medical education: a review of the literature. Med Teach. 33(5):e242-262.

LaDonna KA, Hatala R, Lingard L, Voyer S, Watling C. 2017. Staging a performance: learners' perceptions about direct observation during residency. Med Educ. 51(5):498-510.

Lane J, Lane AM, Kyprianou A. 2004. Self-efficacy, Self-esteem and their impact on academic performance. Soc Behav Pers. 32(3):247-256.

Lave J, Wenger E. 1991. Situated learning: legitimate peripheral participation. Cambridge (England): Cambridge University Press. (Learning in doing.

Lovell B. 2018. What do we know about coaching in medical education? A literature review. Med Educ. 52(4):376-390.

Luft J. 1969. Of human interaction. Palo Alto (CA): National Press Books.

Mann K, van der Vleuten C, Eva K, Armson H, Chesluk B, Dornan T, Holmboe E, Lockyer J, Loney E, Sargeant J. 2011. Tensions in informed self-assessment: how the desire for feedback and reticence to collect and use it can conflict. Acad Med. 86(9):1120-1127.

Mann KV. 2002. Thinking about learning: implications for principlebased professional education. J Contin Educ Health Prof. 22(2): 69-76.

Molloy E, Boud D. 2013. Seeking a different angle on feedback in clinical education: the learner as seeker, judge and user of performance information. Med Educ. 47(3):227-229.

Nicholls JG. 1979. Development of perception of own attainment and causal attributions for success and failure in reading. J Educ Psychol. 71(1):94-99.

Novack DH, Epstein RM, Paulsen RH. 1999. Toward creating physicianhealers: fostering medical students' self-awareness, personal growth, and well-being. Acad Med. 74(5):516-520.

Novack DH, Suchman AL, Clark W, Epstein RM, Najberg E, Kaplan C. 1997. Calibrating the physician. Personal awareness and effective patient care. Working group on promoting physician personal awareness, American Academy on Physician and Patient. JAMA 278(6):502-509.

Ramani S, Konings K, Mann KV, van der Vleuten C. 2017a. Uncovering the unknown: a grounded theory study exploring the impact of self-awareness on the culture of feedback in residency education. Med Teach. 39(10):1065-1073.

Ramani S, Konings KD, Ginsburg S, van der Vleuten C. 2019. Twelve tips to promote a feedback culture with a growth mind-set: swinging the feedback pendulum from recipes to relationships. Med Teach. 41(6):625-631.

Ramani S, Konings KD, Mann KV, Pisarski EE, van der Vleuten C. 2018 About politeness, face, and feedback: exploring resident and faculty perceptions of how institutional feedback culture influences feedback practices. Acad Med. 93(9):1348-1358.

Ramani S, Post SE, Konings K, Mann K, Katz JT, van der Vleuten C. 2017b. It's just not the culture": a qualitative study exploring residents' perceptions of the impact of institutional culture on feedback. Teach Learn Med. 29(2):153-161.

Rangachari D, Brown LE, Kern DE, Melia MT. 2017. Clinical coaching: evolving the apprenticeship model for modern housestaff. Med Teach. 39(7):780-782.

Regehr G, Eva K. 2006. Self-assessment, self-direction, and the self-regulating professional. Clin Orthop Relat Res. 449:34-38.

Rich JV. 2017. Proposing a model of co-regulated learning for graduate medical education. Acad Med. 92(8):1100-1104.

Rider EA, Gilligan MC, Osterberg LG, Litzelman DK, Plews-Ogan M, Weil AB, Dunne DW, Hafler JP, May NB, Derse AR, et al. 2018. Healthcare at the crossroads: the need to shape an organizational culture of humanistic teaching and practice. J Gen Intern Med. 33(7): 1092-1099.

Rochat P, Broesch T, Jayne K. 2012. Social awareness and early self-recognition. Conscious Cogn. 21(3):1491-1497.

Ryan RM, Deci EL. 2000. Self-determination theory and the facilitation of intrinsic motivation, social development, and well-being. Am Psychol. 55(1):68-78.

Ryan RM, Deci EL. 2017. Self-determination theory: basic psychological needs in motivation, development, and wellness. New York (NY) Guilford Press.

Sargeant J. 2015. Reflecting upon multisource feedback as 'assessment for learning'. Perspect Med Educ. 4(2):55-56.

Sargeant J, Armson H, Chesluk B, Dornan T, Eva K, Holmboe E, Lockyer J, Loney E, Mann K, van der Vleuten C. 2010. The processes and dimensions of informed self-assessment: a conceptual model. Acad Med. 85(7):1212-1220.

Sargeant J, Lockyer J, Mann K, Holmboe E, Silver I, Armson H, Driessen E, MacLeod T, Yen W, Ross K, Power M. 2015. Facilitated reflective performance feedback: developing an evidence- and theory-based model that builds relationship, explores reactions and content, and coaches for performance change (R2C2). Acad Med. 90(12): 1698-1706.

Sargeant J, Lockyer JM, Mann K, Armson H, Warren A, Zetkulic M, Soklaridis S, Könings KD, Ross K, Silver I, et al. 2018. The R2C2 model in residency education: how does it foster coaching and promote feedback use? Acad Med. 93(7):1055-1063.

Sargeant J, Mann K, Ferrier S. 2005. Exploring family physicians' reactions to multisource feedback: perceptions of credibility and usefulness. Med Educ. 39(5):497-504.

Sargeant J, Mann K, Manos S, Epstein I, Warren A, Shearer C, Boudreau M. 2017. R2C2 in action: testing an evidence-based model to facilitate feedback and coaching in residency. J Grad Med Educ $9(2): 165-170$.

Sargeant J, Mann K, Sinclair D, van der Vleuten C, Metsemakers J. 2007. Challenges in multisource feedback: intended and unintended outcomes. Med Educ. 41(6):583-591.

Sargeant J, Mann K, Sinclair D, Van der Vleuten C, Metsemakers J. 2008a. Understanding the influence of emotions and reflection upon multi-source feedback acceptance and use. Adv in Health Sci Educ. 13(3):275-288.

Sargeant J, Mann K, van der Vleuten C, Metsemakers J. 2008b. Directed" self-assessment: practice and feedback within a social context. J Contin Educ Health Prof. 28(1):47-54.

Sargeant J, McNaughton E, Mercer S, Murphy D, Sullivan P, Bruce DA 2011. Providing feedback: exploring a model (emotion, content 
outcomes) for facilitating multisource feedback. Med Teach. 33(9): 744-749.

Sargeant JM, Mann KV, van der Vleuten CP, Metsemakers JF. 2009 Reflection: a link between receiving and using assessment feedback. Adv Health Sci Educ Theory Pract. 14(3):399-410.

Schein EH. 2017. Organizational culture and leadership. 5th Edition. ed. Hoboken (NJ): Wiley.

Sender Liberman A, Liberman M, Steinert $Y$, McLeod P, Meterissian S. 2005. Surgery residents and attending surgeons have different perceptions of feedback. Med Teach. 27(5):470-472.

Telio S, Ajjawi R, Regehr G. 2015. The "educational alliance" as a framework for reconceptualizing feedback in medical education. Acad Med. 90(5):609-614.

Telio S, Regehr G, Ajjawi R. 2016. Feedback and the educational alliance: examining credibility judgements and their consequences. Med Educ. 50(9):933-942.

Ten Cate TJ. 2013. Why receiving feedback collides with self determination. Adv Health Sci Educ Theory Pract. 18(4):845-849.

Ten Cate TJ, Kusurkar RA, Williams GC. 2011. How self-determination theory can assist our understanding of the teaching and learning processes in medical education. AMEE guide No. 59. Med Teach. 33(12):961-973.

Ten Cate TJ, Snell L, Mann K, Vermunt J. 2004. Orienting teaching toward the learning process. Acad Med. 79(3):219-228.

van de Ridder JM, Berk FC, Stokking KM, Ten Cate OT. 2014. Feedback providers' credibility impacts students' satisfaction with feedback and delayed performance. Med Teach. 37(8):1-8.

van de Ridder JM, McGaghie WC, Stokking KM, ten Cate OT. 2015a. Variables that affect the process and outcome of feedback, relevant for medical training: a meta-review. Med Educ. 49(7):658-673.

van de Ridder JM, Peters CM, Stokking KM, de Ru JA, Ten Cate OT. 2015b. Framing of feedback impacts student's satisfaction, self-efficacy and performance. Adv Health Sci Educ Theory Pract. 20(3): 803-816.

van der Vleuten CP, Schuwirth LW, Driessen EW, Dijkstra J, Tigelaar D, Baartman LK, van Tartwijk J. 2012. A model for programmatic assessment fit for purpose. Med Teach. 34(3):205-214.
VandeWalle D, Cron WL, Slocum JW. Jr. 2001. The role of goal orientation following performance feedback. J Appl Psychol. 86(4):629-640.

VandeWalle D, Cummings LL. 1997. A test of the influence of goal orientation on the feedback-seeking process. J Appl Psychol. 82(3): 390-400.

VandeWalle D, Ganesan S, Challagalla GN, Brown SP. 2000. An integrated model of feedback-seeking behavior: disposition, context, and cognition. J Appl Psychol. 85(6):996-1003.

Vermunt JD, Verloop N. 1999. Congruence and friction between learning and teaching. Learn Instr. 9(3):257-280.

Watling C. 2014a. Cognition, culture, and credibility: deconstructing feedback in medical education. Perspect Med Educ. 3(2):124-128.

Watling CJ. 2014b. Unfulfilled promise, untapped potential: feedback at the crossroads. Med Teach. 36(8):692-697.

Watling C. 2015. When I say ... learning culture. Med Educ. 49(6): 556-557.

Watling C. 2016. The uneasy alliance of assessment and feedback. Perspect Med Educ. 5(5):262-264.

Watling C, Driessen E, van der Vleuten CP, Lingard L. 2014. Learning culture and feedback: an international study of medical athletes and musicians. Med Educ. 48(7):713-723.

Watling $C$, Driessen $E$, van der Vleuten CP, Vanstone $M$, Lingard $L$. 2012. Understanding responses to feedback: the potential and limitations of regulatory focus theory. Med Educ. 46(6):593-603.

Watling C, Driessen $E$, van der Vleuten $C P$, Vanstone $M$, Lingard $L$. 2013a. Beyond individualism: professional culture and its influence on feedback. Med Educ. 47(6):585-594.

Watling C, Driessen $E$, van der Vleuten CP, Vanstone $M$, Lingard L. 2013b. Music lessons: revealing medicine's learning culture through a comparison with that of music. Med Educ. 47(8):842-850.

Watling CJ, Ginsburg S. 2019. Assessment, feedback and the alchemy of learning. Med Educ. 53(1):76-85.

Watling CJ, LaDonna KA. 2019. Where philosophy meets culture: exploring how coaches conceptualise their role. Med Educ. 53(5): 467-476. 